\title{
PBL - Problem Based Learning for Companies and Clusters
}

\author{
Ileana Hamburg \\ Institut Arbeit und Technik WH Gelsenkirchen, Munscheidstr. 14 \\ D-45886 Gelsenkirchen \\ 0049/002091707265 \\ hamburg@iat.eu \\ Gabriel Vladut \\ IPA-SA Craiova \\ Str. Stefan cel Mare, 12, 200130, Craiova, Dolj, Romania \\ 0040/251 418882 \\ office@ipacv.ro
}

\section{Learning in SMEs}

Small and medium sized companies (SMEs) assure economic growth in Europe [8]. The financial crisis and the economic recession have hit SMEs hard in the Europe 28 (EU28) and the economic conditions remain difficult. Many of these companies are micro enterprises, having few resources and difficulties in facing technological, economic and financial changes.

Cluster development particularly learning methods for urban logistics by means of smart specialisation strategies and creation of competitive niches - Joint Action Plan development and implementation - is not enough researched.

Putting together companies and research institutions belonging to the Clusters on middlelong term objectives, for planning the development of the skills and qualification of their personnel is an effective way for creating permanent links between the research and the industrial environment. This attitude has several beneficial effects:

- Pushes industrial companies to link technological and market development to human resources qualification with a foresight of future trends.

- Can fill the cultural gap between industrial companies and R\&D entities, creating osmosis between these two worlds.

- Stimulates companies to overcome the short-term vision of immediate interest and to cooperate with other companies on more ambitious targets.

The following Figure shows some characteristics of clusters and networks. 
Figure 1: Clusters and Networks [14].

\begin{tabular}{ll}
\hline Networks & Clusters \\
\hline $\begin{array}{l}\text { Networks allow firms access to } \\
\text { specialized services at lower costs }\end{array}$ & $\begin{array}{l}\text { Clusters attract needed specialized services } \\
\text { to a region }\end{array}$ \\
\hline Networks have restricted membership & Clusters have open membership \\
\hline $\begin{array}{l}\text { Networks are based on contractual } \\
\text { agreement }\end{array}$ & $\begin{array}{l}\text { Clusters are based on social values that } \\
\text { foster trust and encourage reciprocity }\end{array}$ \\
\hline $\begin{array}{l}\text { Networks make it easier for firms to } \\
\text { make complex products }\end{array}$ & $\begin{array}{l}\text { Clusters generate demand for other firms } \\
\text { with a variety of similar and related } \\
\text { capacities }\end{array}$ \\
\hline Networks are based on cooperation & $\begin{array}{l}\text { Clusters take both cooperation and } \\
\text { competition }\end{array}$ \\
\hline Networks have common business goals & Clusters have collective visions \\
\hline
\end{tabular}

Source: Adapted from Rosenfeld (2001)

Referring learning, the most popular form of learning in SMEs is the informal one, which accounts for over $75 \%$ of the learning taking place in organizations today. Informal learning is the unofficial, unscheduled, impromptu way people learn to do their jobs. Most learning does not occur during formal training programmes. It happens through processes that are not structured or supported by an employer or an organized formal course. [2], [9]. Most companies, however, focus on and recognize only formal learning programs, losing valuable opportunities and outcomes.

Blended learning can combine the positive aspects of different learning approaches, classroom-based learning and e-Learning, formal and informal ones [6], [13]. By mixing learning styles and different dimensions of learning suitable for SMEs at the course level the usage of blended learning opportunities as a suitable way to learn in SMEs could be improved and so this increases or keeps up competitiveness/surviving of the companies.

The term blended learning is used in the literature for a combination of traditional off-line methods of learning with online methods (i.e. web-based ones) [12]. Within blended learning, classroom based learning is combined with computer-mediated instructions [10], [11], but also various event-based activities (face-to-face class rooms, live e-Learning, selfpaced learning) are combined.

Important aspects of SMEs blended learning could be self-paced learning, mix of methods and media, quality, time flexibility, learner-centered, motivation, flexibility, accessibility and workplace-related learning.

The trainees have the possibility to choose when they study, distance and schedules 
becoming irrelevant. The students are not required to take into account each other's time restrictions, can also choose content necessary to their tasks. In some projects like SIMPEL [4], the use of e-learning in SMEs has particularly analyzed. The conclusions were that properly developed training based on e-Learning not only contributes to improve competences of SME staff, but also to create a growing repository of knowledge.

This knowledge can be continuously provided to employees at a determined time. ELearning has a great potential for the expansion of educational opportunities but it is to consider that "social presence is a strong enabler of satisfaction also in a computer conference" [13].

Results of projects show that SMEs are restricted in the efficient use of different forms of learning and ICT for learning and in adequate management learning approaches [4]. In the following we present the Problem Based Learning (PBL) as an efficient form for SMEs and particularly for clusters of SMES and its ICT support [1], [12].

PBL should be adopted outside academic contexts i.e. as an excellent method of training for SMEs. It allows the learner to develop skills relevant to the needs of the company, it is conducted in a work based environment, it provides them with the skills to sustain the company beyond the initial training, it is low cost and it directly solves problems for the SME providing an immediate return [11]. Donnelly [12] highlighted that little is known about the use of technology in PBL. Learning methods by using PBL and new technologies within clusters are missing.

\section{PBL}

Problem Based Learning (PBL) is an educational strategy introduced at McMaster University, Canada in 1969 [6]. PBL strategy uses real problems to motivate staff and students learning. The PBL rationale is compatible with modern educational principles and approaches which will lead to the achievement of the following objectives [7]:

1) Better acquisition and retrieval of Knowledge related to context and integrate many disciplines.

2) Motivate the students, and provide responsibility of learning

3) Develop the ability of self-learning and metacognition

4) Adapt the learning needs of the students

5) Develop the skills

6) Develop interpersonal skills, the ability to work in team

Many factors are needed in order to achieve a successful PBL that leads to achievement of acquisition of retrieval knowledge. Those factors are: 
1) Prior knowledge and its activation are very important for achievement and increasing the interest in the subject matter.

2) Well-constructed problem will stimulate discussions and will increase the time spent in the tutorial group and in self-study.

3) Competences and behavior of the tutor that maintains the discussion to the context of the problem

4) Student self determination

5) A well-functioning team

6) Group Dynamics

Figure 2 shows elements of different educational theoris applicable within PBL.

Figure 2: Educational theories and PBL

\section{Educational Application in PBL \\ theory / Element}

Information Students use their prior knowledge to generate learning objectives.
processing

The learning regarding the problem will resemble the future situations in which the knowledge acquired will be applied.

Students have the opportunity to expand and elaborate their gained knowledge.

\begin{tabular}{ll}
\hline Collaborative & The tutorial group gives each student an opportunity to present \\
Learning & what he/she finds from different resources during the self-learning \\
& process.
\end{tabular}

Selfdetermination different factors, both intrinsic.

Control In PBL, students define the objectives to be achieved, in a certain defined time.

Behaviorism The problem will stimulate the students to learn (antecedent), students will acquire knowledge (behavior) and students will apply this knowledge to solve the problem (consequence).

Social Cognitive Learning in PBL is due to interaction between the problem as a stimulus, the needs of the learner, the effectiveness of the tutorial group and the abilities of the student to compile the needed information from different resources and discuss these findings.

Source: Barrows (1986) 


\section{Teaching PBL}

Steps which will consider in our projects by teaching PBL and corresponding questions are [12], [13]:

1. Clarifying the task - The purpose of the first step is to explain the task, to agree on the meaning of the various words and terms and on the situation described in the problem. Knowledge possessed by the group members or retrieved from a dictionary can be used Questions:

- Do you understand words, terms and notions?

- Do you agree on what they mean?

2. Defining the problem - The group discuss and reach an agreement on the issues, which need explanation.

Questions:

- What are the problems?

- What are the sub problems?

- Select the problems/sub problems

3. Brainstorming - Aspects on basis of prior knowledge are collected and ideas to structure the problem are expressed. Explanations are arranged into tentative solutions.

4. Rating of Brainstorming outcomes

5. Formulating learning objectives to cover knowledge deficits - Group reaches consensus on the learning objectives; tutor ensures learning objectives are focused, achievable, comprehensive, and appropriate.

Questions

- What do you need to learn before you can solve the case problems?

- Write down the learning goals

- Where can you learn about it?

6. Self-study of the group participants. This phase offers students possibility to acquire a more profound knowledge of theories at the root of the problem. The group members collect information individually with respect of defined learning objectives. Information is collected from the literature but also from other sources (library, journals, internet etc.)

7. Rating of possible solutions and working out a final solution - Group shares results of private study. The tutor checks learning and may assess the group.

8. Reflection and feedback of all participants on the case, the process and the tutor, to improve the learning process. Also it is very important the students validate the course and give their comments on the quality of the problem as well as on the quality of the group process and the tutor's performance

Questions:

- What have you learnt?

- Use it for solving the case problem!

The tutors/trainers of the PBL group play a central role as a facilitator in the PBL process, guiding and supporting the students. The tutor / trainer has to check the understanding, 
ensure group achieves their learning goals, to encourage asking questions and explaining themselves, to introduce use of diagrams and drawings, to foster clinical reasoning and to provide feedback.

In PBL, students need to take a more active part in the organization of the process than in traditional lectures. Students more or less become each other's teachers.

\section{ICT Support in PBL}

Within the project Archimedes (www.archimedes2014.eu) we develop a framework for organizational problem-based learning and support the use of this form of learning. It is expected that these approaches will be widely adopted in entrepreneurial education and SMEs. PBL will be supported by an ICT platform taking into consideration the PBL steps described below.

The platform is in development by using TikiWiki. TikiWiki, also known as Tiki, is an open source Content Management System (CMS). It provides many rich features like websites, forum, chat, wiki, blogs, quiz, calendar, document management, social software and many more. It is highly configurable and is mainly used in companies to organize tasks and to work collaboratively.

Tiki has proven to be a good ICT solution for collaborative working and will be used as platform for PBL. The following figures show screenshots of the ICT platform supporting PBL.

Rooms are e available for group discussions and the libraries should contain references which allow students to research for their PBL cases.

Figures 3 and 4 show the ICT support of some PBL steps by using the platform developed within Archimedes (www.archimedes-tiki.eu). 


\section{Archimedes Learning Platform}

Problem based learning in SMEs

Figure 3. PBL steps visualized on the ICT platform.

\section{Archimedes Learning Platform \\ Problem based learning in SMEs}

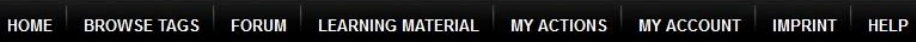

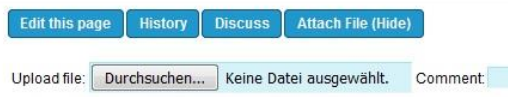

Testproblem

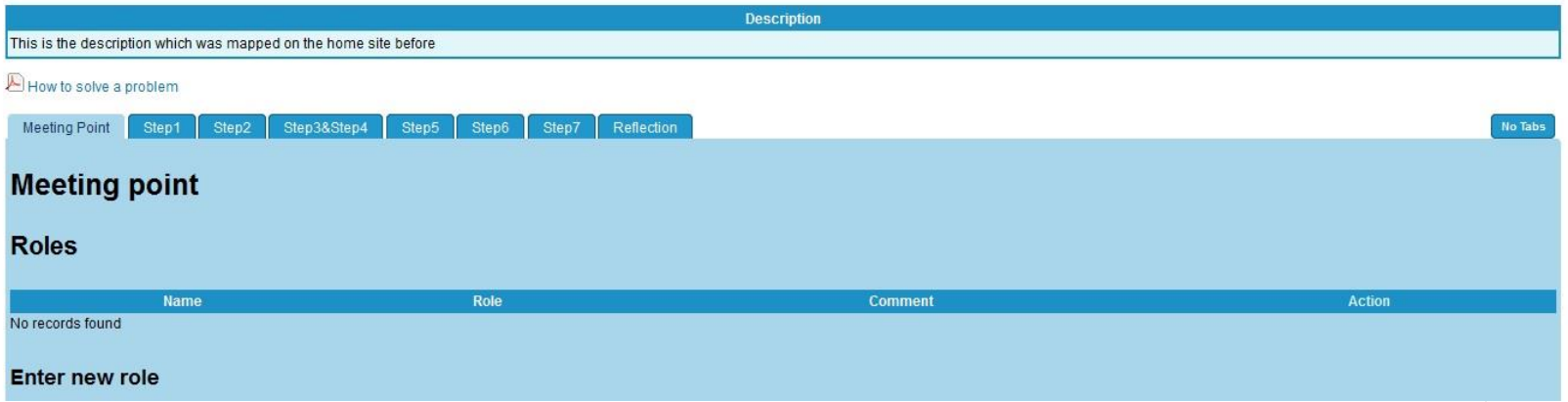

Figure 4. PBL steps visualized on the ICT platform

Clusters represent the means to gather innovations and solutions in order to implement smart specialisation on a regional scale. [15]. PBL as a collective form of learning and knowledge management is particularly efficient in clusters of SMEs which are involved in the development of similar or complementary products having to solve similar problems. 


\section{Conclusions}

The paper presents the learning methods in SMEs particularly the Problem Based Learning (PBL) as an efficient form for SMEs and in clusters. PBL strategy uses real problems to motivate staff and students learning.

Until now the authors tested the ICT supported PBL in single SMEs situated in own countries. The next step is to develop a methodology for using ICT supported PBL in clusters. The efficiency not only depends on the generation and dissemination of innovative learning methods but also on detection of factors which hinder its use like own strategies and learning culture. SMEs have to understand the competitive advantage of PBL in clusters like an innovative collective presence in the local market.

\section{References}

[1] Aarchus Technical College, Standards for Qualifications in. Entrepreneurship Learning. http://www.masht-gov.net/advCms/documents/

Standards for_Qualifications_in_Entrepreneurship_Learning.pdf, 2013.

[2] Admiraal W. and Lockhorst, D. 2009. E-Learning in Small and Medium-sized Enterprises across Europe: Attitudes towards Technology, Learning and Training. International Small Business Journal (27), 743.

[3] Barrows, H.S. 1986. Taxonomy of problem-based learning methods. Medical Education 20, 481-486.

[4] Beer, D., Busse, T., Hamburg, I. and Oehler, C. (eds.) 2008. "Improving eLearning practices in SMEs. Papers. Heidelberg: Springer, 231-240.

[5] Bell, S. 2010. Project-Based Learning for the 21st Century: Skills for the Future, The Clearing House: A Journal of Educational Strategies, Issues and Ideas, 83:2, 39-43.

[6] Donnelly, R. 2006. Blended problem-based learning for teacher education: Lessons learnt learning. Media and Technology, 31(2), 93-116.

[7] European Commission: Annual Report on European SMEs 2013/2014: A Partial and Fragile Recovery.

[8] Gaffar, A. M and Abdalla, M. E. 2011. The Seven Steps of PBL Implementation: Tutor's Manual

[9] Hamburg, I. 2014. Improving education and training impact on competitive advantages in SMEs. In: International journal of innovative research in electronics and communications (IJIREC) 1, no. 4, 54-60.

[10] Hamburg, I. and O'Brien, E. 2014. Using strategic learning for achieving growth in SMEs. Journal of information technology and application in education 3(2), 77-83.

[11] Hamburg, I. and O'Brien, E. 2014. Engaging SMEs in cooperation and new forms of learning. In: Computer and information science 7, no. 1, 9.

[12] Moebs, S., Weibelzahl, S., Tomadaki, E. and Scott, P. (eds.) 2006. Innovative 
Approaches for Learning and Knowledge Sharing, EC-TEL 2006 Workshops Proceedings, ISSN 1613-0073, 10-17.

[13]PBL step by step | UM PBL PREP www.umpblprep.nl/pbl-step-by-step

[14] Rosenfeld, S. A. 2001. Backing into Clusters: Retrofitting Public Policies. Integrating Pressures: Lessons from Around the World. Paper presented at the John F. Kennedy School Symposium Harvard University. Regional Technology Strategies, Inc.

[15] Tambunan, T 2005. Promoting Small and Medium Enterprises with a Clustering Approach: A Policy Experience from Indonesia. Journal of Small Business Management, 43(2), 138-154. 